\title{
"OS LEÕES EM ÁFRICA": FUTEBOL E POLÍTICA NO IMPÉRIO COLONIAL PORTUGUÊS (1954)
}

"Lions in Africa": football and politics in the Portuguese Colonial Empire (1954)

“Leones en África”: fútbol y política en el Imperio Colonial portugués (1954)

JOÃO MANUEL CASQUINHA MALAIA SANTOS ${ }^{*}$

\footnotetext{
' Universidade Federal de Santa Maria. Santa Maria - RS, Brasil.

*Professor do Departamento de História da Universidade Federal de Santa Maria. (jmalaia@gmail.com) ORCID id: https://orcid.org/0000-0001-7154-3860
}

Artigo recebido em $1^{\circ}$ de julho de 2019 e aprovado para a publicação em 8 de outubro de 2019. 


\section{RESUMO}

Num conturbado contexto político e de valorização da excepcionalidade do colonialismo português por parte do governo salazarista, o Sporting Clube de Portugal fez uma excursão de jogos de futebol às suas duas maiores colônias na África, Angola e Moçambique, com atuações também em Joanesburgo e Leopoldville. Por meio da análise de periódicos da imprensa da metrópole e das colônias africanas, buscamos entender as relações entre o futebol e a política colonial portuguesa, a difusão do discurso do lusotropicalismo e da exaltação das obras do "gênio colonial português", além das tensões, esportivas e raciais, dessa experiência de convívio imperial.

PALAVRAS-CHAVE: Colonialismo português; Excursões; Futebol; Racismo; África.

\section{ABSTRACT}

In a troubled political context and in times of appreciation of the exceptionality of Portuguese colonialism by the Salazar government, Sporting Clube de Portugal made a tour for football matches in its largest colonies in Africa, Angola and Mozambique, with performances in Johannesburg and Leopoldville as well. Through the analysis of press journals in the metropolis and the African colonies, we sought to understand the relations between football and Portuguese colonial politics, the diffusion of lusotropicalismo discourse and the exaltation of the works of the "Portuguese colonial genius", besides the racial and sports tensions of this imperial experience.

KEYWORDS: Portuguese colonialism; Tours; Football; Racism; Africa.

\section{RESUMEN}

En un contexto político difícil y en tiempo de apreciación de la singularidad del colonialismo portugués por el gobierno de Salazar, Sporting Clube de Portugal hizo una gira con partidos de fútbol en las dos colonias más grandes de África, Angola y Mozambique, con actuaciones también en Johannesburgo y Leopoldville. A través del análisis de la prensa periódica de la metrópoli y de las colonias africanas, tratamos de comprender las relaciones entre el fútbol y la política colonial portuguesa, la propagación de expresión del lusotropicalismo y la exaltación de las obras del "genio colonial portugués", más allá de las tensiones, deportivas y raciales, de esta experiencia de convivencia imperial.

PALABRAS ClaVE: Colonialismo portugués; Giras; Fútbol; Racismo; África. 


\section{INTRODUÇÃO}

$\mathrm{N}$ a primeira metade dos anos 1950, a equipe de futebol do Sporting Clube de Portugal

foi a principal equipe portuguesa e a mais engajada em disputas internacionais. Entre as temporadas 1950/1951 e 1953/1954, o clube conquistou os quatro títulos nacionais portugueses de futebol, sagrando-se ainda campeão da Taça de Portugal também na temporada 1953/1954. Entre 1951 e 1953, a equipe visitou o Brasil para torneios e amistosos internacionais. Ao fim da temporada 1953/1954, entre julho e agosto, o Sporting, cujo símbolo é um leão, fez uma digressão pelo continente africano para jogos amistosos organizados por suas filiais em Angola e Moçambique. Além das atuações nas colônias portuguesas, realizou jogos em Joanesburgo, contra a seleção do Transvaal do Sul, e no Congo belga, contra a seleção de Leopoldville.

Os resultados e os placares mostram superioridade da equipe da capital portuguesa. Foram 12 jogos, com 11 vitórias e um empate, 55 gols marcados e 14 sofridos. No entanto, os números podem enganar, e olhar apenas para o que aconteceu no campo não revela 0 significado dessa viagem. Para o presidente do clube, Carlos Cecílio Nunes Gois Mota, secretário da Procuradoria-Geral da República e que pertenceu à Legião Portuguesa, milícia oficial do governo salazarista (Madeira, 2007), a digressão dos "leões" na África era um projeto de propaganda política. Mota acompanhou pessoalmente a delegação e mobilizou personagens do poder colonial e da imprensa, tanto da metrópole quanto das colônias.

A viagem aconteceu num dos períodos mais delicados da política colonial de Manuel Salazar. Em meio a um debate internacional sobre o processo de condenação à situação colonial na África e na Ásia, o governo português buscava navegar "contra o vento" (Alexandre, 2017) e criar elementos para fazer com que suas colônias se pensassem como parte do Império. Foi o período da exaltação do lusotropicalismo, o conjunto de narrativas a partir da nação imperial que explicavam o excepcionalismo colonial português, "narrativas que nomearam, edificaram, retificaram, codificaram e finalmente reproduziram o pensamento imperial/colonial" (Ribeiro, 2013: 544).

A esse conjunto de ideias, juntavam-se medidas do governo salazarista e celebrações que pudessem envolver representantes de todo o Império. A alteração da nomenclatura de colônias para províncias pela Lei Orgânica do Ultramar (1953) e a mudança no Estatuto do Indígena, criando a categoria de assimilado para os africanos (1954), eram exemplos das ações do governo no sentido de mostrar um colonialismo mais brando. Foi também o tempo das celebrações dos 25 anos do governo Salazar (1953) e da viagem do presidente português Craveiro Lopes às colônias africanas (1954), eventos em que ficava clara a atuação da imprensa do ultramar no sentido da adesão ao programa político salazarista. 
Todo esse processo, no entanto, também sofria reveses que revelavam a violência e as fragilidades do colonialismo português. Em fevereiro de 1953, em São Tomé, o tenente-coronel Carlos de Souza Gorgulho, a mando do governo colonial, comandou o que ficou conhecido como "Massacre de Batepá", após uma recusa de trabalho dos forros por conta das condições precárias de trabalho impostas pelo governo colonial. 0 evento vitimou "um número indeterminado de forros, o grupo etnocultural dominante em São Tomé e Príncipe" (Rodrigues, 2018: 63).

O contexto político em que aconteceu a digressão do Sporting foi extremamente conturbado e carregado de dramaticidade. Quando o Sporting chegou a Moçambique, ao fim de junho de 1954, os enclaves portugueses na Índia de Dadrá e Nagar-Aveli passaram a sofrer ataques de grupos nacionalistas da União Indiana (Alexandre, 2017), processo que continuou durante todo o tempo em que o Sporting esteve na África.

Por conta de toda essa efervescência política, o Estado Novo investiu em transferências culturais de um lado e de outro (Peralta e Domingos, 2013). Era preciso criar zonas de contato com experiências culturais de lado a lado, e as práticas esportivas fizeram parte desse processo. Além do aumento das digressões de clubes portugueses em direção às colônias africanas e também no sentido contrário, ${ }^{1}$ jornais de grande circulação em Portugal, Angola e Moçambique passaram a fazer inúmeros pedidos pela realização dos Jogos do Império e pela participação de clubes do ultramar na Taça de Portugal. ${ }^{2}$

Com base na perspectiva da história imperial, analiso a maneira como a digressão do Sporting foi relatada em setores-chave da imprensa popular imperial, "o meio pelo qual políticos e o público se enfrentavam via jornalistas, editores e proprietários, e onde as notícias se misturavam com entretenimento e muitas vezes se confundiam" (Lewis, 2017: 465).

A cobertura da imprensa da metrópole e das colônias serviu para que o Império português pudesse ser lido por um amplo público, agindo no sentido de ampliar a experiência imperial. As crônicas escritas por membros da delegação do clube português, como "Os Leões em África", do goleiro Carlos Gomes, e, principalmente, a "Rota da Saudade", de Mota, nos mostram uma exaltação ao portuguesismo, ao "gênio colonial português" e ao próprio Império ultramarino.

A cobertura da imprensa imperial serviu também para mostrar as possibilidades de fissura que o futebol trazia para a reverberação de um discurso uníssono na rede imperial, revelando quão ancorado numa divisão racial estava esse colonialismo (Araújo, 2013). 


\section{REDES IMPERIAIS: FUTEBOL E IMPRENSA NA POLÍTICA COLONIAL}

produção historiográfica sob a perspectiva da história imperial auxilia numa melhor
compreensão de como se davam as dinâmicas interativas entre as diferentes partes dos impérios e nos ajudar a pensar tanto na influência imperial da metrópole nas colônias quanto no impacto dessa política imperial nas próprias metrópoles (Sinha, 1998). As atividades de trocas de experiências entre a metrópole e suas colônias podem ser vistas como elementos de circulação de uma rede imperial, que conecta pessoas, bens e capital por meio de seus pontos nodais (Magee e Thompson, 2010). No caso dos impérios europeus, esses pontos nodais eram os portos e, na segunda metade do século XX, os aeroportos dos sítios coloniais e metropolitanos.

Essa materialidade da rede alimentava uma série de discursos articulados por meio de seus circuitos de comunicação. Como aponta Lester (2001), a maioria das pessoas que vivia nas metrópoles apenas imaginava como era o ambiente nas colônias, o que levava os grupos nas colônias a se organizarem e adentrarem esses circuitos de comunicação, ajudando a moldar o entendimento sobre as pessoas e os lugares do Império.

No contexto colonial, a mídia impressa e radiofônica desempenhou um papel preponderante nesses circuitos de comunicação, gerando um senso de inclusão em distantes pontos do Império. Ampliando o conceito de "comunidades imaginadas" de Anderson (2008), John B. Thompson (1995) apontou que os meios de comunicação nesse período desenvolveram uma poderosa rede transnacional, gerando sentimentos de pertencimento numa comunidade imperial mais ampla do que a nacional. Para Mageen e Thompson (2010), os jornais atuavam dentro das redes imperiais, ligando pessoas, nutrindo um senso de compromisso cultural, transcendendo fronteiras e reforçando o senso de pertencimento da comunidade britânica.

As experiências dos Impérios contemporâneos foram permeadas de atividades esportivas, atraindo setores da mídia que tinham o objetivo de circular notícias entre metrópole e colônia, colaborando para a construção do sentimento de uma aura imperial. 0 chamado "esporte imperial", ou as manifestações esportivas que envolviam grupos das metrópoles e das colônias, pode ser observado como "símbolos políticos e laços culturais" (Magan, 2010).

As práticas esportivas mobilizavam o governo metropolitano em sua política colonial, dramatizando as tensões do Império (Melo, 2012), sendo amplamente retratada nas páginas de jornais e revistas.

Nuno Domingos $(2011,2012)$ afirma que a análise de fenômenos esportivos, particularmente o futebol, levantam questões importantes para a compreensão do colonialismo português e de seus projetos de dominação ideológicos e políticos, processos e resistências, além da relação 
entre esferas do poder central e dos poderes locais. Ele aponta a criação por colonos de filiais dos clubes europeus na África, os meios de comunicação e as excursões de clubes metropolitanos como responsáveis pela criação de experiências imperiais, em que colonos podiam se sentir efetivamente representantes da metrópole e a própria metrópole podia ali se fazer sentir presente.

Apesar de as digressões dos clubes portugueses serem apontadas como um dos três pilares na formação das narrativas de um futebol metropolitano em Lourenço Marques — podendo-se estender para as demais cidades coloniais africanas portuguesas - , pouca atenção foi dada às viagens de clubes metropolitanos às colônias portuguesas, situação diferente na literatura sobre o império britânico.

Um dos primeiros pensadores a se dedicar a compreender os tours esportivos imperiais foi C. L. R. James (1963), no contexto da luta pela Independência da Índia. 0 autor apontou um aspecto importante para análises sobre atividades que colocavam frente a frente equipes metropolitanas contra equipes coloniais: a necessidade de observar que as paixões sociais e políticas, negadas nos canais normais, se expressavam muito bem no críquete e em outros jogos, precisamente por serem jogos.

Tais digressões, e também aquelas de grupos coloniais em direção à metrópole, se tornaram um dos pontos de análise privilegiados na historiografia imperial britânica — seja como elemento para cimentar as relações coloniais, como Allen (2007) tratou as primeiras digressões de times ingleses de rúgbi em solo sul-africano, seja como um presságio para o futuro do Império Britânico, como McDevitt (2004) mostrou que a imprensa imperial abordou as derrotas para seleções da Nova Zelândia (1905) e da África do Sul (1906), ambas nas ilhas britânicas.

A própria natureza competitiva das provas esportivas estabelecia um clima de medição de capacidades que era explorado pela imprensa que cobria os eventos. Por esse motivo, olhar para o conjunto de atividades desenvolvidas na viagem do Sporting e a cobertura por jornais da metrópole e das colônias africanas nos ajudam a entender os elementos culturais e ideológicos que cimentavam essa rede imperial, mas também seus pontos de tensão, que podem ser presságios para o futuro do Império. Em artigos que opõem necessariamente metropolitanos e coloniais, devem-se perceber, além do "alinhamento da imprensa ao Estado Novo" (Fonseca, 2017: 264), possíveis críticas à política colonial portuguesa. A descrição da prática desportiva muitas vezes pode ter mais liberdade, passando despercebida pela censura, como nos alerta Robert Edelman (1993), ao analisar os jornais esportivos soviéticos do período do stalinismo.

O corpus principal de fontes é composto por periódicos publicados na metrópole e nas colônias portuguesas na África. Foram analisados jornais portugueses (O Século, Diário de 
Notícias, Diário de Lisboa, A Bola, Record, Mundo Desportivo e Jornal do Sporting), moçambicanos (Guardian, Guardian Desportivo, Notícias da Beira, Notícias da Tarde e Brado Africano) e angolanos (Angola Desportiva e Voz do Planalto).

Os jornais escolhidos foram aqueles indicados como os de maior popularidade na metrópole e nas colônias africanas em trabalhos como os de Rocha (2000); Fonseca (2014); Garcia, Kaul, Subtil e Santos (2017); Garcia, Alves e Léonard (2017); Kumar (2017). Além disso, o Jornal do Sporting foi importante fonte de análise, uma vez que expressa a visão institucional do clube. ${ }^{3}$ Passemos à compreensão da viagem do Sporting como um projeto não apenas esportivo, mas também político, cuidadosamente pensado por seu presidente Mota.

\section{O LUGAR DO SPORTING NO "ESPETÁCULO FASCISTA"}

K

umar aponta um aspecto importante desse tipo de viagem esportiva:

As digressões africanas das principais equipes portuguesas e o ciclo de inaugurações dos estádios nos anos 1950, a par da presença de alguns elementos do regime nas direções dos principais clubes portugueses, podem com alguma facilidade integrar o mesmo quadro analítico ou uma periodização política da história do futebol português e do seu lugar no espetáculo fascista (2017: 165).

Com base na digressão do Sporting e na atuação de Mota, destacado membro do regime salazarista, pode-se, portanto, compreender um pouco melhor a dimensão política do futebol e, mais precisamente, do Sporting no espetáculo fascista. Num período de reformas legislativas no tocante à política imperial e de contestações e reveses internacionais, encontros que opusessem conjuntos metropolitanos e coloniais deveriam ser cuidadosamente planejados e executados. Foi assim que o presidente do Sporting, Carlos Nunes Cecílio Gois Mota, pensou essa digressão.

Procurador-geral da República e comandante dos Centuriões, um dos batalhões da Legião Portuguesa (Kumar, 2014), ${ }^{4}$ Mota atuou na direção do Sporting desde 1934, conquistando a presidência do clube em 1953. A despeito da dificuldade imposta pelo governo português para que clubes jogassem no exterior, ${ }^{5}$ ele levou o Sporting ao Brasil para a disputa de torneios internacionais importantes, como as duas edições da Taça Rio (1951 e 1952) e a Taça Rivadávia Corrêa Meyer (1953). Na primeira viagem, Mota escreveu relatórios para Salazar, no sentido de mostrar a dimensão diplomática da excursão ao Brasil (Kumar, 2017).

Num contexto de aproximação da intelligentsia salazarista com o intelectual brasileiro Gilberto Freyre (Pinto, 2009: 470), Mota soube gerar forças para novos círculos luso-brasilei- 
ros. Ele visitou o Jornal dos Sports, no Rio de Janeiro, onde manteve "cordial conversa" com o proprietário, Mario Filho, ${ }^{6}$ autor de 0 negro no futebol brasileiro, obra prefaciada por Gilberto Freyre, um dos articuladores do lusotropicalismo português. Além disso, ministrou palestras, como a de título "O desporto e a cultura",7 no Gabinete Português de Leitura, em evento organizado pelo embaixador português no Brasil, Antônio de Faria. Em 1952, o presidente do Sporting foi ainda condecorado como oficial da Ordem do Cruzeiro, em solenidade no Itamaraty, organizada pelo ministro das Relações Exteriores, João Neves da Fontoura.

Podemos compreender como Mota pensava a condução do clube e a própria digressão às colônias africanas por meio dos editoriais do Jornal do Sporting durante sua gestão, a partir de 1953. Na mesma edição em que o clube anunciou sua ida à África, podia ser lido num editorial:

Há largos anos o Sporting vem procurando orientar sua política clubística e a sua mentalidade clubística no sentido de se tornar um elemento ativo e eficiente na vida da Nação e, particularmente, no ressurgimento intelectual moral e cívico da Raça Portuguesa. ${ }^{8}$

No mesmo texto, diz-se que o esporte poderia e deveria ser usado em Portugal para "ligar as diferentes regiões, promovendo o seu mútuo conhecimento, a sua mútua estima e, por este meio, a unidade de pensamento e de ideal entre a população do país, tão necessária à unidade da Nação".

Em outro editorial, esclarecia-se o que movia o clube na viagem à África portuguesa:

Nesta hora de alta de entusiasmo "leonino" e fervor patriótico, não podemos ficar calados perante 0 alto significado da visita do Sporting às Províncias Ultramarinas de Moçambique e Angola. Orgulhosos do esforço e dedicação dos propagadores deste ideal que é uma continuação de nós próprios, sentimos que esta viagem, Rota da Saudade, como lhe chamou o grande sportinguista que chefia a Embaixada, é o melhor elo de ligação entre as vontades inigualáveis que mantém bem viva a chama sportinguista na Metrópole e na África Portuguesa. ${ }^{9}$

Ao longo da digressão, Mota fez discursos em prol do colonialismo português em todos os eventos dos quais participou nas colônias africanas, alimentando as páginas dos jornais do Império e ligando as notícias do futebol do clube à política colonial salazarista. Foi assim logo na chegada a Lourenço Marques, na sede da filial local, quando proferiu o desejo de que a viagem do Sporting "significasse acima de tudo um forte laço de amizade a unir mais os irmãos do Ultramar e da Metrópole". ${ }^{10}$

Na despedida de Moçambique, no espetáculo em homenagem ao clube no Teatro Gil Vicente lotado, Mota realizou discurso que terminou com um "viva vibrante a Portugal, um 
viva que fosse escutado em toda a terra portuguesa e até na Índia Portuguesa, a Índia do nosso coração". ${ }^{11}$ Ele afirmou que o Sporting não era apenas um clube metropolitano, "pois nos seus atletas existiam valores do Ultramar", ${ }^{12}$ referindo-se a Pacheco (Macau), Juca (Moçambique) e Mendonça (Angola).

Em Luanda, em recepção na filial local com representantes do esporte angolano, Mota proferiu discurso destacando novamente que o Sporting era um clube "bem português" por ter em seu time principal jogadores de "Macau, Moçambique e Angola". Terminou com "frases repassadas do mais são patriotismo", fazendo alusão "ao momento que nossa nação está vivendo pela covarde agressão levada a efeito numa das parcelas do território nacional, fazendo correr o sangue português". ${ }^{13}$

0 dirigente máximo do Sporting foi pessoalmente às redações dos jornais, dando entrevistas ou deixando textos para serem publicados. Após visitar, por exemplo, o Notícias da Beira e o Guardian, os dois jornais concorrentes da capital de Manica e Sofala (Moçambique) publicaram o mesmo texto, no qual podia ser lido que a Beira era o lugar "onde o patriotismo domina e eleva o espírito, integrando todos no sentido histórico do Portugal eterno" ${ }^{14}$

Mota levou também a delegação diversas vezes às sedes dos governos das províncias, das câmaras municipais e até dos bispados. ${ }^{15}$ Foi assim em todas as cidades por onde passaram, tanto em Moçambique quanto em Angola. Além disso, as autoridades locais estiveram sempre presentes aos jogos. Em Angola, foi registrado inclusive o apoio do presidente da Câmara Municipal de Nova Lisboa, Serafim Moler, para que se concretizasse o "intercâmbio desportivo Metrópole-Províncias Ultramarinas". ${ }^{16}$

No encalço das agressões da Dadrá e Nagar-Aveli, Mota levou a delegação ao governador-geral de Moçambique, no Palácio da Ponte Vermelha, sede do governo em Lourenço Marques, declarando que a "embaixada leonina" classificava a atitude como "atentatória ao brio nacional" e que "o sentimento patriótico leonino" fazia com que todos estivessem revoltados com a violência da União Indiana. Por isso, apresentavam-se todos "em armas" pela defesa da unidade imperial e dos territórios indianos que, se eram "há séculos portugueses, portugueses hão-de continuar a ser". ${ }^{17}$

O presidente do Sporting, em sua crônica para o Mundo Desportivo, declarou que esses jogadores faziam parte de um grupo que, "movido por um ideal mais alto, haviam oferecido a sua vida para que Portugal continuasse íntegro, uno e indivisível" . ${ }^{18} 0$ governador teria agradecido, dizendo que "faria ciente ao governo da nação tão patriótica atitude". ${ }^{19}$

As crônicas de Mota para o Mundo Desportivo cumpriam importante papel na descrição das colônias para o imaginário do leitor metropolitano e como propaganda do salazarismo e 
do colonialismo português. Os jogos não são descritos, a não ser contra a equipe sul-africana. 0 dirigente usou esse espaço para dar a conhecer as expressões que considerava máximas do colonialismo português.

0 presidente do clube lisboeta descreveu a chegada à cidade de Lourenço Marques, onde "europeus e indígenas ${ }^{20}$ saúdam-nos entusiasticamente". Na passagem pelo bairro indígena de Xipamanine, "os pretos e as consortes, velhos e novos, homens mulheres e crianças, agitam bandeirinhas e gritam em coro: Sporting! Sporting! [...] Viva Portugal!" . ${ }^{21} 0$ dirigente fez questão de voltar ao bairro durante sua estadia na capital moçambicana. Levou a delegação do Sporting para confirmar o "portuguesismo desta linda terra". A visita fora oferecida pela Associação Africana de Futebol de Lourenço Marques e "por um numeroso grupo de africanos adeptos deste clube".

Emocionado com a maneira alegre com que os negros africanos enfrentavam as precárias condições no bairro de Xipamanine, Mota não se cansava de elogiar o orgulho dos africanos em tentarem reproduzir modos e hábitos portugueses e por terem orgulho de se sentir portugueses. Com lágrimas nos olhos, o presidente do clube teria ainda mais certeza do "porvir do Império edificado com sofrimento e dedicação, devoção e espírito de sacrifício". ${ }^{22}$

Na continuidade de suas crônicas, descreveu Lourenço Marques como a "terra portuguesa de inigualável portuguesismo", prova do "gênio colonizador" português, "expressão do seu valor incontestado [...] padrão de um novo mundo que desabrocha para o futuro grandioso que a espera na civilização desta parcela de Portugal". ${ }^{23}$ Quelimane era o "expoente da tradição centenária da nossa adaptação ao meio e aos hábitos dos povos", com sua economia agropastoril, seu "encanto e misteriosa sedução", suas areias duras da praia, onde faziam pistas para automóveis em "velocidade de loucura".

Na Beira, afirmava que toda a população via em Salazar um "chefe reconhecido e incontestado" e que a cidade, como obra de resgate do Estado Novo nacionalista, "garantia as tradições seculares da nossa História", ato "dos altos desígnios do maior gênio latino da governação pública". A população "ordeira e trabalhadora" era um "exemplo vivo" do que era capaz "Portugal, como mestre dos povos colonizadores".24

Luanda era o "grande centro de progresso e de expansão, fruto da fé, da perseverança, da heroicidade inigualável dos pioneiros e dos que as suas pegadas de glória souberam seguir". Benguela era onde havia oportunidades para pôr à prova "nosso temperamento, as virtudes da nossa raça e os nossos defeitos". Afirmava ser este o motivo pelo qual Deus fizera o mundo tão grande e Portugal tão pequeno: demonstrar "quanto pode o homem animoso, 
dinâmico, entusiasta, trabalhador", dando aos portugueses "esse gênio sublime" , com capacidade de criar um "Império em todos os oceanos e em todos os continentes" ${ }^{25}$

Mota descreveu também a viagem à reserva de caça de Gorongosa, organizada pela filial do clube da Beira. A descrição revela a exuberância da natureza e cada um dos diferentes animais que a delegação conseguiu ver e caçar. Mostrava assim aos leitores portugueses mais um pouco da pujança do Império Ultramarino português. ${ }^{26}$

A outra visita descrita foi ao Campo Militar Boane. 0 presidente do Sporting contou sobre os "guerreiros negros", ficando "maravilhado e inebriado" ao ouvir soldados africanos cantarem "com toda a força dos seus pulmões" o hino de Portugal. Narrou o diálogo que teve com um desses soldados:

- Que acabou você de cantar?

— Os "Heróis do Mar" — responde-me o soldado que soube ser de Inhambane.

- E que lhe lembra esse cântico? — Ataquei eu curioso pela resposta que veio, imediata e sem a mínima hesitação.

— Lembra os feitos dos nossos antepassados!

- Mas sente alguma coisa quando canta?

— Sim, vontade de combater por Portugal!

Por Portugal... foi a expressão que me ficou na mente. ${ }^{27}$

Ao posicionarmos o Sporting nesse contexto, principalmente por meio de ações, palavras e textos de seu presidente, podemos compreender como Mota pensava a atuação do clube pelo qual era responsável. Mas nem só de elogios ao colonialismo e à obra do "gênio colonial português" estavam carregadas as páginas da imprensa imperial. Algumas tensões podem ser percebidas, a despeito da censura à imprensa instaurada pelo regime salazarista.

\section{FUTEBOL, RACISMO E POLÍTICA}

lém de todo o discurso elogioso ao sistema imperial português, aspectos contestató-
rios podem ser percebidos nas páginas da imprensa imperial, mais precisamente em alguns jornais de Moçambique e de Angola. Os jogos se mostram oportunidades para que a imprensa metropolitana revelasse seu racismo na visão das diferentes partes do Império seja por meio das charges publicadas, seja por meio das crônicas da delegação do Sporting. Serviu também para que a imprensa colonial fizesse críticas relacionadas à suposta superioridade do futebol metropolitano e, pontualmente, ao racismo da direção do Sporting. 
Quase todos os jogos suscitaram dúvidas quanto ao verdadeiro significado dos placares por parte da imprensa colonial, e comparações com o futebol metropolitano foram inevitáveis. Para o cronista de O Brado Africano, a ida do Sporting a Moçambique era o "último exame para a apreciação das diferenças e distâncias que existem entre os portugueses moçambicanos e os metropolitanos". ${ }^{28}$ Exceto nos jogos contra as seleções da Zambézia (9x0), da Beira (7x0), e contra o Sporting de Luanda (11x2), nos outros seis jogos contra equipes coloniais, os placares foram por diferença de dois gols em quatro deles, diferença de três gols em outro, e ainda houve um empate, contra a seleção de Lourenço Marques. Tais resultados foram contestados nos jornais de Moçambique e Angola por meio de muitas críticas, principalmente às arbitragens.

O empate foi o resultado que mais colocou em causa a superioridade do Sporting. 0 Guardian, afirmava, "como sempre dizia", que os jogadores da metrópole não eram melhores que os de Moçambique. ${ }^{29} 0$ Notícias da Beira aproveitava o resultado para voltar a defender como legítimo o desejo de uma equipe moçambicana participar da Taça de Portugal. 0 Brado Africano, conhecido por defender os interesses dos moçambicanos (Rocha, 2000), afirmou que os jogadores que atuaram por aquele selecionado nem de longe representavam o melhor dos atletas de Lourenço Marques. Referia-se aos jogadores negros dos clubes da Associação Africana de Futebol, que reunia os clubes dos subúrbios da capital moçambicana (Domingos, 2012), excluídos da possibilidade de participar dos encontros. Na conclusão, afirmava: "Lourenço Marques não precisa de mais exames." ${ }^{30}$

A crítica do Brado Africano dava voz a uma das contradições da alegada excepcionalidade do colonialismo português: o racismo. Ainda que não instituído legalmente, o racismo está presente nas descrições da população negra africana na imprensa, sobretudo a metropolitana (Almeida, 2016).

Os jornais esportivos portugueses publicaram inúmeras charges sobre a digressão. Nelas, um traço comum pode ser percebido: a estigmatização e a inferiorização da África, do negro e do futebol africano. As charges publicadas apresentam o Sporting representado por um leão humanizado que domina, ridiculariza e até engole o futebol africano, representado por negros com uniformes de futebol. ${ }^{31}$ Numa delas, são colocados negros uniformizados num campo de futebol, carregando lanças e comunicando, frente à surpresa do árbitro branco, que haviam sido chamados para "caçar leões", 32 sendo ridicularizados por não conhecerem questões da cultura da metrópole.

Em outra charge, negros aparecem na selva com vestimentas tribais, amedrontados com a chegada de um leão com o uniforme do Sporting e chuteiras: a "fera" que vinha da metrópole. ${ }^{33}$ 
Os artigos dos integrantes da delegação do Sporting para os jornais metropolitanos são reveladores da percepção sobre os africanos negros. As pessoas negras das crônicas simplesmente não têm nome. Mota não citou o nome do soldado com o qual travou conversa sobre o hino, mencionada antes. Carlos Gomes não citava os nomes dos jogadores negros nem de pessoas negras com as quais interagiu. Referindo-se a um jogo que foram ver do "campeonato local, entre pretos", em Leopoldville, ficou incrédulo com o "magnífico estádio" lotado com 60 mil espectadores: "Com milhares de cabeças negras deu-nos um aspecto extraordinário e ainda mais fascinante e bizarro se tornou porque em cada preto ou preta havia um fato de tecido espampanante." ${ }^{34}$

Carlos Gomes também não citou o nome do atacante negro da seleção do Lobito. ${ }^{35}$ Tratava-se de Chipenda, futuro jogador do Benfica e da Académica de Coimbra, que posteriormente se tornou um dos líderes do Movimento Pela Libertação de Angola (MPLA) na luta pela Independência daquela colônia. No entanto, essa questão veio à tona com particular interesse no jogo que a equipe realizou em Joanesburgo.

Na União Sul-Africana, onde vigoravam leis de segregação racial, a partida era um importante gesto simbólico de aproximação entre aquele país e Portugal. A União Sul-Africana foi um dos países que mais apoiaram "a defesa dos interesses coloniais de Portugal nas Nações Unidas" (Meneses, 2014: 42). A partida ficou marcada nas páginas da imprensa imperial por um manancial de discursos que atestavam o diferencial do colonialismo português, representações emocionadas de "portuguesismo" frente ao apartheid sul-africano.

O governo português regulava a emigração de trabalhadores moçambicanos negros em direção às minas de ouro de Rand, na União Sul-Africana, desde 1875 (Zamparoni, 2004). As mesmas linhas de trem que ligavam Joanesburgo a Lourenço Marques para o escoamento das minas serviram para levar os portugueses de Moçambique à cidade sul-africana para ver o Sporting. "Uma grande excursão" de trem foi anunciada, com a saída de Lourenço Marques na sexta-feira, às 20 horas, e retorno na madrugada de domingo. 0 pacote dava direito à "obtenção de salvo-conduto", bilhete de trem, cama nas duas noites de viagem, café da manhã no dia 31 de julho e $1^{\circ}$ de agosto e ingresso para o Rand Stadium. ${ }^{36}$

De acordo com os jornais da imprensa imperial, cerca de três mil trabalhadores negros moçambicanos que viviam na África do Sul e brancos moçambicanos vindos de Lourenço Marques estiveram presentes no jogo. Com a presença do general Abranches Pinto, embaixador de Portugal, o clube português chegou a estar perdendo por 4 a 1, mas conseguiu reverter 0 placar para 5 a 4, com um gol no último minuto de jogo, com direito a invasão de campo da torcida do Sporting. A carga dramática do fim partida deu tons ainda mais emocionais aos 
relatos de manifestações de "portuguesismo". A união de negros e brancos era descrita, comentada, celebrada e fotografada para registro nas páginas da imprensa imperial.

O técnico do Sporting, Tavares Silva, descreveu para a imprensa metropolitana que "o público da raça negra dava também largas ao seu regozijo". ${ }^{37}$ O Século colocou uma fotografia de jogadores sendo carregados por torcedores negros e brancos, descrevendo na legenda que os milhares de portugueses que estavam presentes entraram no campo para levar "em triunfo os campeões nacionais" 38

A Bola descreveu o triunfo "festejado quer pelas centenas de portugueses de L. Marques, quer pelos milhares de indígenas naturais de Moçambique que estão a trabalhar nas minas da União" ${ }^{39} 0$ Record preferiu destacar que aquela vitória teria sido sentida como uma vitória de Portugal: "Houve no fim muita lágrima; o nome do nosso país ouvia-se de boca a boca." ${ }^{40} 0$ Jornal do Sporting foi ainda mais incisivo. Ao descrever o fim do jogo, mostrava que "trabalhadores das minas e nossos compatriotas de raça negra exultavam e sofreram pelo seu Sporting e pelo seu Portugal". ${ }^{41}$

Mota escreveu sua crônica com o subtítulo "Os onze de Rand" e iniciou afirmando que o esporte era "um meio fácil de propaganda, pela sua perturbante aliciação em todos os campos da afeição humana". Na conclusão, dizia: "Os briosos rapazes da nossa turma realizaram tarefa de alto significado político e de retumbante prestígio internacional." 42 A Bola publicou ainda um telegrama enviado pelo embaixador, general Abranches Pinto, ao ministro da Educação Nacional, parabenizando pela forma como o Sporting transformou "pesada derrota em honrosa vitória". ${ }^{43}$

Os jornais moçambicanos também deram destaque às vitórias. 0 Notícias da Tarde, de Lourenço Marques, destacou a atuação da torcida, "residentes e visitantes — sem preocupações de clubismos ou de raças, todos irmanados do mesmo fervor patriótico". Dizia que os sul-africanos sentiam admiração pela "grande lição de lusitanismo" dada pelos portugueses de "exaltação patriótica em que europeus e africanos, sim, mas todos portugueses acima de tudo, roucos de tanto gritar, loucos de entusiasmo e alegria [...] aos gritos de 'Viva Portugal'!". ${ }^{44}$

0 correspondente do Notícias da Beira descreveu "brancos, africanos de Moçambique que labutam nessas terras, todos à uma, saltam ao campo e pegam em ombros aqueles bravos rapazes" ${ }^{45} \mathrm{O}$ cronista Manuel Luís Pombal, dizendo não ser afeito a "patriotices", descrevia sua memória do jogo: "Passam fugazmente no meu pensamento visões tumultuosas de indígenas nossos erguendo triunfalmente a bandeira nacional." ${ }^{46}$ 
De Angola, A Voz do Planalto descreveu que, ao fim do jogo, "algumas centenas de indígenas moçambicanos trabalhando nas minas da União sacaram em ombros os jogadores do Sporting, numa extraordinária manifestação de portuguesismo". ${ }^{47}$ Em pontos nodais da rede imperial, a notícia de brancos e negros celebrando em união a vitória portuguesa era a materialização do lusotropicalismo e foi amplamente bradada na imprensa.

A partida, no entanto, também ficou marcada pelo afastamento do jogador negro do Sporting, o angolano Mendonça, que não jogou porque Mota aceitou a imposição de segregação racial em vigor na União Sul-Africana como condição para a realização do jogo. Revelando uma incongruência total com o exaltado excepcionalismo colonial português, o jovem atacante dos "Leões" foi afastado do jogo para atender às diretrizes políticas sul-africanas e à aproximação política dos dois governos.

O fato não foi relatado por praticamente nenhum órgão da imprensa imperial, a não ser por duas exceções. A primeira delas, uma breve passagem na crônica de Carlos Gomes para A Bola antes do jogo: "Crê-se que Mendonça não alinhará no sábado, por motivos de discriminação racial." ${ }^{88} \mathrm{~A}$ segunda, muito mais contundente e corajosa, foi escrita pelo diretor do Sporting Clube de Luanda, Trindade Fernandes, em artigo de quase uma página inteira para 0 Angola Desportiva, com o título "Uma imposição que é um ultraje: nem o Sporting nem qualquer outro clube de Portugal deveria pactuar com semelhante e indigno vexame".

0 autor critica a exclusão de Mendonça "por ser da raça preta". As questões teriam a ver com as leis da União Sul-Africana, porém a aceitação do clube não poderia "ter lugar de forma alguma". Fernandes se mostrava incrédulo com a atitude de Mota e com o silêncio dos colegas da imprensa: "Com a mais veemente indignação e repulsa, não aceitamos. E nem compreendemos como possa haver alguém que os possa aceitar." Ressaltava que os dirigentes do Sporting tinham "elementos africanos em suas linhas", portanto nunca poderiam aceitar "semelhantes imposições". Ou jogavam todos os atletas ou não haveria partida: "Não. Não podemos estar de acordo com a facilidade com que Mendonça foi excluído da linha, e esse desacordo é dirigido aos dirigentes do Sporting ou de qualquer outro clube que peque pelas mesmas razões."

Se os dirigentes do Sporting aceitavam Mendonça era por "Ihe reconhecerem qualidades sociais e pessoais" aliadas à técnica, e, portanto, deveriam sair em sua defesa: "Se serve para ganhar campeonatos e para acompanhar os seus colegas em digressões fora das nossas fronteiras, foi porque deu provas definitivas para tal distinção". Conclui o artigo com uma pergunta direcionada aos dirigentes do clube lisboeta: "A que superior interesse se subordinaram para aceitar a imposição sul-africana?" 49 


\section{CONCLUSÃO}

1 análise da digressão do Sporting, por meio da observação da imprensa imperial e da da associação na política imperial portuguesa. Com destacada presença no governo salazarista, Mota soube capitalizar a viagem e a presença do clube em terras africanas com um discurso de valorização da política colonial portuguesa. Seus discursos, suas crônicas e suas atitudes estão intimamente ligadas às posições defendidas pela política do governo de Salazar e buscavam colocar o clube em sintonia com os demais atos do "espetáculo fascista".

A natureza opositória do jogo de futebol e as paixões que se levantaram em lados opostos, todavia, também serviram para alimentar na imprensa africana críticas aos jogadores, ao futebol e aos dirigentes metropolitanos. Se a censura impedia manifestações políticas de oposição na imprensa imperial, as críticas no futebol por vezes passavam despercebidas, podendo ser consideradas uma oposição às demarcações de divisão entre a metrópole e as colônias. A crônica de Trindade Fernandes sobre o afastamento de Mendonça era muito mais que uma crítica esportiva. Tratava-se de uma crítica à complacência com a política discriminatória do apartheid em meio a um forte controle dos meios de comunicação. Ele cobrou duramente Mota por aceitar facilmente o afastamento do jogador e fez uma pergunta insinuando que aquele gesto atendia a um "interesse superior".

Ainda é necessário mergulhar mais a fundo nessas digressões esportivas realizadas entre a metrópole e as colônias do império português. Essas trocas culturais podem nos dar um maior entendimento dos discursos de união em torno do Império, mas também das tensões que vibravam as conexões e os pontos nodais da rede imperial. A reverberação da viagem do Sporting pela imprensa da metrópole e das colônias africanas foi utilizada largamente como mote para divulgar o Império Ultramarino, a excepcionalidade do colonialismo português e até o "portuguesismo" presente nas colônias africanas. Mas serviu também para colocar a claro as cisões no seu interior e, principalmente, suas mazelas racistas, a despeito de toda a tentativa de mostrar o contrário.

Nesse contexto, a história do futebol serve para iluminar os mecanismos políticos que buscavam usar as atividades relacionadas a esse esporte como uma ferramenta de dominação na rede imperial. No entanto, também se mostra como possibilidade para pensarmos as resistências a tais tentativas. 


\section{NOTAS}

1 Clubes portugueses foram a Angola e Moçambique, como as visitas do Benfica e do Marítimo do Funchal (1950) e do Atlético de Lisboa (1951). Experiências no sentido contrário também aconteciam, mas com outros esportes, como as viagens a Portugal dos times moçambicanos de basquete do Ferroviário, em 1951 (Eco dos Sports, Moçambique, 27 de outubro de 1951, p. 15), e de hóquei em patins do Sindicato Nacional dos Empregados do Comércio e da Indústria, em 1955 (Eco dos Sports, Moçambique, 30 de julho de 1955, p. 9 e 15).

2 Na edição de 10 de julho de 1954 de A Bola, na capa, o cronista Aurélio Márcio defende que a Taça de Portugal deveria "ser disputada por todos os clubes incluindo os representantes das ilhas adjacentes e do Ultramar". Em Moçambique, o Guardian Desportivo também defendia a entrada dos clubes do ultramar em competições de futebol na metrópole. Outro moçambicano, o Eco dos Sports, apresentou em sua capa de 29 de dezembro de 1953 a "Petição dos atletas de Moçambique ao Ministério das Colônias" pela realização dos Jogos do Império. Já o Jornal de Angola, no rescaldo da visita do presidente português àquela colônia, publicou em seu editorial de 30 de junho de 1954 o texto de título "As províncias ultramarinas e a reorganização séria do desporto português", requisitando: "Aqui também é Portugal."

3 o sporting não disponibilizou documentos requisitados, como atas de assembleias de sócios, da direção e do conselho, nem nenhum tipo de documento oficial para além do jornal do clube.

4 Pouco se pode afirmar quanto à ligação de Gois Mota com os documentos oficiais da própria Legião Portuguesa. Um ofício do Comando Geral da Legião Portuguesa dá conta de um "indivíduo suspeito" de nome Jorge de Oliveira que insistia em falar com Gois Mota. Fundo Legião Portuguesa. Ofício n. AG2357 LP/SI de 24 de outubro de 1941. LP, AG 2357, NT 1478. Arquivo Nacional Torre do Tombo, Lisboa, Portugal.

5 Havia preocupação do governo salazarista com as viagens de clubes portugueses ao exterior. A direção-geral do Ministério da Educação, por exemplo, negou ao Benfica a possibilidade de realizar três jogos no Brasil em 1947, com receio de o clube português não conseguir representar bem as cores nacionais (Kumar, 2017).

6 Jornal dos Sports, Rio de Janeiro, 16 de julho de 1952, p. 6.

7 Jornal dos Sports, Rio de Janeiro, 11 de julho de 1952, p. 8.

8 Jornal do Sporting, 12 de junho de 1954, p. 3.

9 Jornal do Sporting, 31 de julho de 1954, p. 4.

10 Guardian, $1^{\circ}$ de julho de 1954, p. 6.

11 Guardian Desportivo, 29 de julho de 1954, p. 11.

12 Jornal do Sporting, 7 de agosto de 1954, p. 3.

13 Angola Desportiva, 17 de agosto de 1954, p. 2.

14 Notícias da Beira, 15 de julho de 1954, p. 10, e Guardian, 21 de julho de 1954, p. 5.

15 Ulisses de Oliveira atesta em sua crônica o fato de ficar impressionado com a multidão presente no aeroporto e nas ruas a caminho do hotel. Afirma ainda que todo o grupo foi também recebido pelo cardeal-arcebispo Teodósio Gouveia. Record, 7 de julho de 1954, p. 7.

16 Angola Desportiva, 17 de julho de 1954, p. 7. 
17 Jornal do Sporting, 7 de agosto de 1954, p. 1.

18 Mundo Desportivo, 18 de agosto de 1954, p. 1 e 4.

19 Jornal do Sporting, 7 de agosto de 1954, p. 1.

20 Os portugueses se referiam aos negros africanos como indígenas.

21 Mundo Desportivo, 21 de julho de 1954, p. 1 e 5. Notícias da Tarde, 31 de julho de 1954, p. 6.

22 A crônica sobre o bairro indígena só termina no Mundo Desportivo de 2 de agosto de 1954, p. 1.

23 Mundo Desportivo, 21 de julho de 1954, p. 1 e 5.

24 Mundo Desportivo, 28 de julho de 1954, p. 1 e 4.

25 Mundo Desportivo, 20 de agosto, p. 3 e 8.

26 Mundo Desportivo, 28 de julho, p. 4, e 30 de julho, p. 1.

27 Mundo Desportivo de 2 de agosto de 1954, p. 1.

280 Brado Africano, Moçambique, 26 de junho de 1954, p. 3.

29 Guardian, Moçambique, 19 de julho de 1954, p. 8.

30 Brado Africano, 24 de julho de 1954, p. 2

31 Record, 10 de julho, p. 15, e 10 de agosto, p. 15.

32 Mundo Desportivo, 28 de julho de 1954, p. 1.

33 A Bola, 3 de julho de 1954, p. 4.

34 A Bola, 7 de agosto, p. 5.

35 A Bola, 14 de agosto de 1954, p. 4.

36 Notícias da Tarde, 30 de junho de 1954, p 12, e 7 de julho, p. 12.

37 Diário de Lisboa, $1^{\circ}$ de agosto de 1954, p. 1 e 3.

38 O Século, $1^{\circ}$ de agosto de 1954, p. 5.

39 A Bola, 2 de agosto de 1954, p. 4.

40 Record, 3 de julho de 1954, p. 8.

41 Jornal do Sporting, 7 de agosto de 1954, p. 3.

42 Mundo Desportivo, 18 de agosto de 1954, p. 1.

43 A Bola, 3 de agosto, p. 1.

44 Notícias da Tarde, 2 de agosto de 1954, p. 12.

45 Notícias da Beira, 3 de agosto de 1954, p. 4.

46 Notícias da Beira, 3 de agosto de 1954, p. 12.

47 Voz do Planalto, 5 de agosto de 1954, p.4. 
48 A Bola, 29 de julho, p. 1.

49 Angola Desportiva, 17 de agosto de 1954, p.3.

\section{REFERÊNCIAS BIBLIOGRÁFICAS}

ALEXANDRE, Valentim. Contra o vento: Portugal, o Império e a maré anticolonial (1945-1960). Lisboa: Círculo de Leitores, 2017.

ALLEN, Dean. Tours of Reconciliation: rugby, war and reconstruction in South Africa, 1891-1907. Sport in History, v. 27, n. 2, p. 172-189, 2007.

ALMEIRA, Pedro. Futebol, racismo e media: os discursos da imprensa portuguesa durante o fascismo e pós-Revolução de Abril. Revista de Ciências Sociais, n. 44, jan.-jun. 2016, p. 71-90, 2016.

ANDERSON, Benedict. Comunidades imaginadas: reflexões sobre a origem e a difusão do nacionalismo. São Paulo: Companhia das Letras, 2008.

ARAÚJO, Marta. Challenging Narratives on Diversity and Immigration in Portugal: (De)Politicization of Colonialism and Racism. In: KRETSEDEMAS, P. et al. (orgs.). Migrant Marginality: A Transnational Perspective. Nova York: Routledge, 2013, p. 27-46.

DOMINGOS, Nuno. 0 desporto no Império Português. In: NEVES, J.; DOMINGOS, N. (coords). Uma história do desporto em Portugal: nação, Império e globalização, vol II, 2011, p. 51-107.

DOMINGOS, Nuno. Futebol e colonialismo: corpo e cultura popular em Moçambique. Lisboa: Imprensa de Ciências Sociais, 2012.

EDELMAN, Robert. Serious Fun: a History of Spectator Sport in the USSR. Nova York: Oxford University Press, 1993.

FONSECA, Isadora A. A imprensa e o Império na África portuguesa (1842-1974). Tese (Doutorado em Sociologia) - Instituto de Ciências Sociais, Universidade de Lisboa, Lisboa, 2014.

GARCIA, José L. et al. (eds.) Media and the Portugueses Empire. Cham: Palgrave Macmillan, 2017.

GARCIA, José L.; ALVES, Tânia; LÉONARD, Yves (coords). Salazar, o Estado Novo e os Media. Lisboa: Edições 70, 2017.

JAMES, C. L. R. Beyond a Boundary. Londres: Stanley Paul \& Co., 1963.

KUMAR, Rahul. A pureza perdida do desporto: futebol no Estado Novo. Tese (Doutorado em Sociologia) Instituto de Ciências Sociais, Universidade Nova de Lisboa, Lisboa, 2014.

KUMAR, Rahul. A pureza perdida do desporto: futebol no Estado Novo. Lisboa: Edições Paquiderme, 2017.

LEWIS, Joanna. "Daddy Wouldn't Buy Me a Mau Mau" The British Popular Press \& the Demoralization of Empire. In: SHIPWAY, M. The Rise and Fall of Modem Empires: Reactions to Colonialism, vol. IV. Nova York: Routledge, 2016, p. 465-490.

LESTER, Alan. Imperial Networks: Creating Identities in Nineteenth-century South Africa and Britain. Nova York: Routledge, 2001. 
MADEIRA, João. A legião portuguesa. In: MADEIRA, J.; PIMENTEL, l.; FARINHA, L. (orgs.) Vítimas de Salazar. Estado Novo e violência política. Lisboa: A Esfera dos Livros, 2007, p. 269-288.

MAGEE, Gary; THOMPSON, Andrew. Empire and Globalisation: Networks of People, Goods and Capital in the British World, c. 1850-1914. Cambridge: Cambridge University Press, 2010. MANGAN, J. A. Britain's Chief Spiritual Export: Imperial Sport as Moral Metaphor, Political Symbol and Cultural Bond. The International Journal of the History of Sport, v. 27, n. 1-2, p. 328-336, 2010.

McDEVITT, Patrick. May the Best Man Win Sport, Masculinity, and Nationalism in Great Britain and the Empire (1880-1935). Hampshire: PallGrave MacMillan, 2004.

MELO, Victor A. Pequenas-grandes representações do Império português: a série postal Modalidades Desportivas (1962). Estudos Históricos, v. 25, n. 50, p. 426-446, 2012.

MENESES, Maria P. O olho do furacão? A África austral no contexto da Guerra Fria (década de 70). In: MENESES, A. P.; MARTINS, B. As guerras de libertação e os sonhos coloniais: alianças secretas, mapas imaginados. Lisboa: Almedina, 2014, p. 41-58.

PERALTA, Elsa; DOMINGOS, Nuno (orgs.). Cidade e Império: dinâmicas coloniais e reconfigurações pós-coloniais. Lisboa: Edições 70, 2013.

PINTO, João A. da C. Gilberto Freyre e a intelligentsia salazarista em defesa do Império Colonial português (1951-1974). História (São Paulo), v. 28, n. 1, p. 445-482, 2009.

RIBEIRO, Margarida. Letras do Império: percursos da literatura colonial portuguesa. In: JERÓNIMO, M. B. 0 Império Colonial em questão (sécs. XIX e XX): poderes, saberes e instituições. Lisboa: Edições 70, 2013, p. 515-546.

ROCHA, Idílio. A imprensa de Moçambique. Lisboa: Edição Livros do Brasil-Lisboa, 2000.

RODRIGUES, Inês. Espectro de Batepá: memórias e narrativas do "Massacre de 1953" em São Tomé e Príncipe. Porto: Afrontamento, 2018.

SINHA, Mrinalini. Britain and the Empire: Toward A New Agenda for Imperial History. Radical History Review, n. 72, p. 163-174, 1998.

THOMPSON, John B. The Media and Modernity. A Social Theory of the Media. Cambridge: Polity Press, 1995.

ZAMPARONI, Valdemir. Da escravatura ao trabalho forçado: teorias e práticas. Africana Studia, n. 7, p. 299325, 2004. 